Canu, W. H. (2008). An experiential learning activity demonstrating normal and phobic anxiety. Teaching of Psychology, 35(1): 22-25 (Feb 2008). Published by Taylor \& Francis (ISSN: 1532-8023). DOI: $10.1080 / 00986280701826634$

\title{
An Experiential Learning Activity Demonstrating Normal and Phobic Anxiety
}

Will H. Canu

\begin{abstract}
This article describes an activity for an undergraduate abnormal psychology course that used student-generated data to illustrate normal versus clinically significant anxiety responses related to specific phobias. Students $(\mathrm{N}=37$ ) viewed 14 images of low- or high-anxiety valence and rated their subjective response to each. Discussion in a subsequent class focused on differentiating normal from pathological fear and the theory of predisposed, evolution-linked phobias. Students indicated the exercise was interesting and contributed to their understanding of specific and social phobias.
\end{abstract}


In-class demonstrations can improve the learning outcomes of undergraduates (McKeachie \& Svinicki, 2006).Although abnormal psychology courses educate students about diverse psychological disorders, some syndromes are far removed from most students' personal experience and difficult to illustrate in activities (e.g., the psychotic features of schizophrenia). Instructors have effectively employed active techniques in lessons on rare phenomena such as suicide (Hubbard \& Mclntosh, 1992) and dissociative identity disorder (Rabinowitz, 1989). However, it is just as important to use engaging techniques to illustrate mood and anxiety disorders to help students learn how to differentiate these prevalent diagnoses from the "normal" fear and sadness that everyone experiences.

Because fear is such a universal emotion, instructors can generate it under controlled classroom conditions to facilitate understanding of anxiety disorders. The activity herein integrates students' current emotions and course material to illustrate normal and pathological anxiety, focusing on specific object and social phobias.

\section{METHOD}

\section{Sample}

Participants were undergraduates $(N=37 ; 19$ women, 18 men; 3 freshmen, 8 sophomores, 11 juniors, 15 seniors) taking abnormal psychology at a midsized,Midwestern, public university in spring 2007 , comprising all but 1 student in the class (participating in intercollegiate athletics the day of the exercise). Participants received extra credit (equivalent to one homework assignment) for their efforts. All students completed a written informed consent procedure (approved by the university's institutional review board) several classes prior to this activity. The consent noted exactly what types of stimuli would be presented and offered all students the option to listen to an audio recording of the class session and complete an alternate, out-of-class assignment for the same credit (e.g., a reading and review of Pine\&Shapiro, 2006).Astatement in the consent form specifically urged those with intense fear of the animals or situations depicted in the activity to take this latter option; however, all students in this class elected to participate in the exercise. 


\section{Stimuli}

Stimuli were one high- and one low-anxiety valence image from each of seven categories: insect, canine, spider, snake, enclosed space, group of people, and social confrontation scenes. Figure 1 displays the canine example.
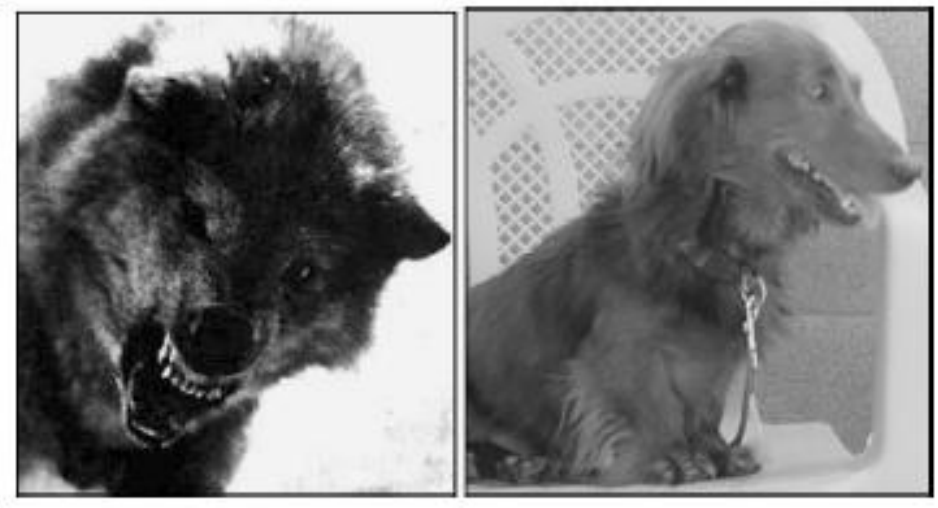

Figure 1. Example stimuli used in demonstration: snarling wolf (high anxiety valence) and dachshund (low anxiety valence).

\section{Experiential Learning Activity}

The activity was embedded in a unit on specific and social phobias. Before beginning, I explained that this was the exercise forwhich students had completed consent and reminded them that I designed it to facilitate understanding of anxieties that are environmentally triggered. I then told students that they could look away if a particular image was unexpectedly unsettling, but that it was desirable to complete all ratings. Next, I projected the stimuli at the front of the classroom (in order): scorpion, dachshund, tarantula, narrow canyon, daddy longlegs, snarling wolf, coiled rattlesnake, crowd looking away, tiny bug, intense confrontation scene, narrow room, crowd facing toward viewer, garter snake, mild confrontation scene. During each 15-sec display, participants recorded ratings of their arousal ("apprehension, fearful thoughts, increased breathing or pulse rate, etc."; 1 = no anxiety response, 10 = very strong anxiety). Very few students evidenced obvious anxiety (e.g., facial grimacing, sharp intakes of breath) during the activity, and I did not notice any outward signs 
of discomfort by the end of the class period. At that point, I inquired whether anyone was experiencing unexpectedly or uncomfortably high anxiety, and no one indicated that was the case. As the class period expired and I collected the anxiety rating forms, I made a final invitation for anyone who felt intense fear during the exercise to see me in my office after class. Again, none in this group did, but should a student do so, a variety of helpful interventions are possible (e.g., deep breathing or other relaxation techniques, referral to the campus counseling center for potential follow-up).

\section{Class Discussion}

To begin class the next day, I presented the students' compiled, anonymous set of anxiety-rating results and summary data (Ms and $S D$ s). I highlighted individual response cells that were greater than $2 S D$ above the mean. Discussion focused on three topics.

The evolutionary nature of fear and phobias. I began by telling students that human phobias have roots in biological adaptation; our ancestors developed heightened vigilance for situations, animals, and other environmental cues that posed evolutionary threats (Mineka, Davidson, Cook, \& Keir, 1984; Ohman, Fredrickson, Hugdahl,\&Rimmo, 1976; Seligman, 1970). The most prevalent targets of phobias fit with this theory, to wit, physical vulnerability (e.g., claustrophobia-fear of enclosed spaces), dangerous animals (e.g., arachnophobia-fear of spiders), and activities that could result in ostracism (i.e., social phobia). From this perspective, phobias represent overarousal in mildly threatening situations (e.g., in arachnophobia, seeing a tarantula nearby) and overgeneralization of vigilance (e.g., fearing a daddy longlegs). Students then discussed how the images in the activity fit the theory and whether they had experienced or witnessed high degrees of anxiety for stimuli that would not pose actual danger to our ancestors.

\section{Differentiating normal from abnormal reactions.}

Another discussion point regarded how to identify unusually high anxiety. Some students suggested flat cutoffs (e.g., "a 7 should be considered high anxiety"), whereas others considered the "scare value" of stimuli important, aswell (e.g., a 7 for the rattlesnake is not equivalent to a 7 for the garter snake). After reviewing measures of central tendency, I instructed the class that scores on tests of psychopathology (e.g., anxiety) 
that are $+2 S D$ above the population mean are unusually high (Kenny, 1987); clinicians use it as a cutoff to indicate problems that could merit intervention (e.g., Barkley \& Murphy, 1998). We then examined their set of responses, putting emphasis on the data points $+2 S D$ above the mean.

Criteria for diagnosis of a phobia. As noted in the Diagnostic and Statistical Manual ofMental Disorders (American Psychiatric Association, 2000), although a degree of anxiety related to environmental cues is common, even in adulthood, most cases are not impairing enough to warrant a diagnosis. The students' data set illustrated this point, as $38 \%$ of the sample rated at least one image $+2 S D$ above the mean. We next evaluated such individual data according to a more stringent standard of pervasiveness: elevated ratings on both the high- and low-valence images in one category (e.g., wolf and dachshund); doing so reduced the prevalence of "abnormal" reactions to $8 \%$. I then emphasized that even pervasive anxiety must be accompanied by substantial maladjustment to be diagnosable. Finally, I likened the process during this activity to employing clinical tools (e.g., structured interviews, Beck Anxiety Inventory [Beck \& Steer, 1990]) to probe the pervasiveness of a "real-life" client's anxiety.

Following this discussion, students rated the learning activity ("Did this exercise help you learn about specific phobias?", "Did this exercise help you learn about social phobia?") on a 5-point scale ranging from 0 (not at all) to 4 (definitely!), as well as their general satisfaction with the experience ("How interesting was this exercise?"; 0 = not at all, 4 = very). Students also completed two open-ended questions; the first of these tapped the "most important" things they learned about phobias as a result of the exercise, and the second solicited any additional comments about the exercise.

Five students absent during this class period did not complete these exercise evaluations.

\section{RESULTS}

\section{Responses to Anxiety-Related Images}

Analyses suggested that the activity facilitated an in-class, mild-to-moderate anxiety response that could generate discussion and understanding of phobic responses. With one exception, all students reported that at least one stimulus evoked some 
arousal (rating >1). Even low-anxiety valence images

evoked notable physical and psychological reactions

(see Table 1).

Table 1. Response to Phobic Anxiety-Evoking Images:

Means, Standard Deviations, and Range of Anxiety

\begin{tabular}{|c|c|c|c|c|c|c|}
\hline Image & $M$ & $S D$ & Range & No. Min. Responses & Two-tailed $t$ & Cohen's $d$ \\
\hline Coiled rattlesnake & 3.19 & 1.81 & $1-8$ & 6 & $4.45^{* * *}$ & 0.54 \\
\hline Garter snake in grass & 2.30 & 1.49 & $1-8$ & 12 & & \\
\hline Snarling wolf & 2.97 & 1.64 & $1-7$ & 7 & $7.31^{* * *}$ & 2.40 \\
\hline Dachshund in chair & 1.00 & 0.00 & - & 37 & & \\
\hline Tarantula on hand & 2.92 & 1.59 & $1-7$ & 7 & $4.56^{4 * 8}$ & 0.73 \\
\hline Daddy longlegs spider on hand & 1.92 & 1.14 & $1-6$ & 17 & & \\
\hline Climber in narrow canyon & 2.43 & 1.73 & $1-7$ & 14 & $3.60^{* *}$ & 0.94 \\
\hline Narrow room/cell & 1.51 & 0.87 & $1-5$ & 23 & & \\
\hline Scorpion in sand & 2.41 & 1.04 & $1-6$ & 6 & $3.10^{* *}$ & 0.60 \\
\hline Tiny bug depicted next to quarter & 1.81 & 0.97 & $1-4$ & 18 & & \\
\hline Intense personal confrontation scene & 1.73 & 1.05 & $1-5$ & 20 & $2.92^{* *}$ & 0.67 \\
\hline Mild personal confrontation scene & 1.22 & 0.48 & $1-3$ & 30 & & \\
\hline Audienœ looking toward the viewer & 1.24 & 0.55 & $1-3$ & 30 & 0 & 0 \\
\hline Audience looking away from viewer & 1.24 & 0.64 & $1-4$ & 31 & & \\
\hline
\end{tabular}

Note. No. Min. Responses = number of participants who rated image at the low end of the observed range. Image names in italics were high-anxiety valence stimuli, with the matching "low" valence item listed directly below. Degrees of freedom for $t$ tests $=36$.

${ }^{* * *} p<.01{ }^{* *} p<.001$.

Two-tailed $t$ tests indicated that pairs of high- and

low-anxiety valence images were experienced differentially,

with moderate to large effect size (see Table 1),

with one exception: Ratings of the images of an audience

looking toward the perceiver (high valence) and

another looking away (low valence) were equivalent,

with both evoking very mild arousal. It is possible that

the brief (15-sec) exposure and the negligible performance

expectations (e.g., no direction to "introduce

yourself to this group") so diluted the stimulus that

the expected arousal occurred only in individuals with

elevated social anxiety.

\section{Learning Outcomes}

On the postactivity evaluation, $56 \%$ strongly endorsed the activity's effectiveness as a teaching tool for specific phobias (responses of either Quite a bit or Definitely!; $M=2.5, S D=0.9$ ), with $34 \%$ responding similarly regarding social phobia $(M=2.2, S D=$ $0.8)$. Many other students responded that the activity 
moderately augmented their understanding of specific and social phobias ( $28 \%$ and $50 \%$, respectively). The vast majority of students indicated that the activity captured their interest at least moderately (26\%), with most reporting that it was either quite $(31 \%)$ or very $(31 \%)$ interesting $(M=2.8, S D=1.1)$.

Open-ended responses regarding the most important points conveyed by the exercise reinforced that it facilitated learning. Example responses included "Causation of phobias is traceable to an evolutionary mechanism which works for us most of the time," "I never knew that phobias could be so debilitating until this discussion," "That the statistics, tendencies, trends discussed in class do hold true in an actual sample," "Most people have fears that elevate their stress levels, but actual phobias that interfere with daily functioning are less common," and "I had no idea that phobias would cause such an intense feeling of anxiety by just seeing an image of the fear target." Other general comments included "Excellent use of statistics, visual aids, and lecture to illustrate principles of anxiety disorders," "I thought it was interesting how we could use our own responses to compare and contrast to the class," and "Much better than just going over random data about phobias."

\section{DISCUSSION}

Using data from students' ratings of anxiety in response to selected images can facilitate discussion regarding phobias and differentiating normal from abnormal responses, and, by employing formal consent procedures in advance, those with substantial fears are protected from harm or embarrassment. By and large, the stimuli that one expects to be of high anxiety valence led to higher ratings than paired low-valence images. This difference illustrated that some fears are adaptive and normal, but that more pervasive fear is indicative of phobia. Feedback regarding this exercise suggests that students enjoyed it and it aided their learning. Future replication of this exercise might be improved by selecting audience stimuli that include a more intense high-valence image (e.g., an audience ridiculing or taunting a performer) and collecting a concurrent physiological measure (e.g., heart rate) for a subsample of volunteers. 


\section{REFERENCES}

American Psychiatric Association. (2000). Diagnostic and statistical manual of mental disorders (4th ed., text revision). Washington, DC: Author.

Barkley, R. A., \& Murphy, K. R. (1998). Attention-deficit hyperactivity disorder: A clinical workbook (2nd ed.). New York: Guilford.

Beck, A. T., \& Steer, R. A. (1987). Manual for the revised Beck Anxiety Inventory. San Antonio, TX: Psychological Corporation.

Kenny, D. A. (1987). Statistics for the social and the behavioral sciences. Boston: Little, Brown.

Hubbard, R. W., \& McIntosh, J. L. (1992). Integrating suicidology into abnormal psychology classes: The Revised Facts on Suicide Quiz. Teaching of Psychology, 19, 163166.

McKeachie, W. J., \& Svinicki, M. (2006). McKeachie's teaching tips: Strategies, research, and theory for college and university teachers (12th ed.). Boston: Houghton Mifflin.

Mineka, S., Davidson, M., Cook, M.,\&Keir, R. (1984).Observational conditioning of snake fear in rhesus monkeys. Journal of Abnormal Psychology, 93, 355-372.

Ohman, A., Fredrickson, M., Hugdahl, K., \& Rimmo, P.-A. (1976). The premise of equipotentiality in human classical conditioning: Conditioned electrodermal responses to potentially phobic stimuli. Journal of Experimental Psychology: General, 105, 313-337.

Pine, D. S., \& Shapiro, T. (2006). A developmental evolutionary perspective on two anxiety disorders. In P. S.

Jensen, P. Knapp, \& D. A. Mrazek (Eds.), Toward a new diagnostic system for child psychopathology: Moving beyond the DSM (pp. 58-77). New York: Guilford.

Rabinowitz, F. E. (1989). Creating the multiple personality: An experiential demonstration for an undergraduate abnormal psychology class. Teaching of Psychology, 16, 6971.

Seligman, M. E. P. (1970). On the generality of the laws of learning. Psychological Review, 77, 406-418. 


\section{NOTES}

1. The complete set of images is available on request.

2. I thank my abnormal psychology students, who participated in this activity and allowed me to use their responses, and Ruth Ault, who provided sage advice on the preparation of this article.

3. Send correspondence to Will H. Canu, Department of Psychology, Appalachian State University, P.O. Box

32109, 22 Joyce Lawrence Lane, Boone, NC 28608; email: canuwh@appstate.edu. Will was a faculty member at the University of Missouri-Rolla when these data were collected. 